\title{
Desempenho de Vacas Jovens Nelore em Pastagens de Brachiaria brizantha Suplementadas ou não com Fósforo/Cálcio e Ração Durante a Seca
}

\author{
Maria Luiza Franceschi Nicodemo ${ }^{1}$, Sheila da Silva Moraes $^{1}$, Luiz Roberto Lopes de S'Thiago, \\ Manuel Cláudio Motta Macedo ${ }^{1,5}$, Elizângela Luiz Caxias ${ }^{2}$, Ériklis Nogueira ${ }^{3}$, Jairo Mendes \\ Vieira $^{1}$, Eustáquio Camargo Vaz $^{4}$
}

\begin{abstract}
RESUMO - Grande parte dos problemas do rebanho de cria, incluindo baixa taxa de prenhez e baixos pesos à desmama, está diretamente relacionada ao consumo inadequado de energia e/ou proteína, ou a deficiências de minerais e vitaminas. Procurou-se estudar o efeito da suplementação de cálcio e fósforo, com ou sem proteína e energia, sobre o desempenho produtivo de vacas de cria em pastagem de B. brizantha cv. Marandu, durante a seca. Todas as fêmeas receberam mistura mineral completa nas águas; na seca, os tratamentos foram: mistura mineral completa, mistura mineral sem fosfato bicálcico com ou sem concentrado protéico-energético. Nas condições deste trabalho, a suplementação protéico-energética não teve efeitos significativos sobre o ganho de peso e a condição corporal das vacas, bem como sobre o peso dos bezerros ao parto e à desmama. O intervalo entre partos não diferiu entre os tratamentos, mas as vacas primíparas que receberam ração apresentaram menor número de dias vazios. A ausência de suplementação de P durante o período seco não acarretou prejuízos significativos nas taxas reprodutivas dos animais. Os efeitos de tratamento foram minimizados pelas boas condições das pastagens.
\end{abstract}

Palavras-chave: B. brizantha, bovino de corte, cerrado, concentrado, intervalo de partos, minerais, seca

\section{Performance of Young Nellore Cows in Brachiaria brizantha Pastures Supplemented or not with Dicalcium Phosphate and Concentrate During the Dry Season}

\begin{abstract}
Many problems of the beef herd, including low pregnancy rates and low weaning weights, are related to inadequate intakes of energy and /or protein, as well as to minerals and vitamins deficiencies. The objective of the present study was to evaluate the performance of beef cows supplemented with phosphorus/calcium with or without energy/protein during the dry season. All cows received complete mineral mixtures during the wet season; during the dry season, the imposed treatments were: complete mineral mixtures or mineral mixtures lacking dicalcium phosphate, supplemented or not with concentrate. In the present conditions, protein/energy supplement showed no significant effects on weight gains and body condition of cows, as well as on calf weight at calving and at weaning. The calving interval did not differ between treatments, but primiparous heifers that received concentrate exhibited less open days. Phosphorus supplementation during the dry season did not affect negatively reproductive performance. The treatment effects were minimised by the good pasture condition.
\end{abstract}

Key Words: B. brizantha, beef cattle, “cerrados”, concentrate, dry season, minerals, open days

\section{Introdução}

Nutrição é o fator mais importante influenciando o desempenho reprodutivo dos rebanhos de cria. De fato, baixa taxa de prenhez e baixos pesos à desmama têm sido atribuídos ao consumo inadequado de energia e/ou proteína (Simms et al., 1993). Além desses nutrientes, as pastagens do Centro-Oeste são também deficientes em minerais, como fósforo, zinco, cobre, cobalto, iodo e sódio (Tokarnia \& Dobereiner, 1976; Sousa et al., 1983; Sousa et al., 1985). A deficiência de fósforo está relacionada com a baixa taxa de concepção, anestro, estro irregular, redução na atividade ovariana, alta incidência de cistos foliculares e queda geral na fertilidade (Maas, 1987; Hurley \& Doane, 1989).

A concentração de fósforo nas forrageiras acompanha a concentração de nitrogênio, com valores especialmente baixos durante a estação seca, nas plantas maduras. Apesar disso, as respostas ao fósforo suplementar são mais dramáticas na estação chuvosa, quando os aportes de energia e de proteína deixam de ser limitantes para o ganho de peso (Van Niekerk, 1975). No caso de fêmeas em reprodução,

\footnotetext{
${ }^{1}$ Pesquisadores, Embrapa Gado de Corte, BR 262, Km 04, CP 154, CEP 79002-970, Campo Grande, MS. E.mail: sgcnpgc@cnpgc.embrapa.br

${ }^{2}$ Bolsista de iniciação científica da Embrapa Gado de Corte.

3 Médico veterinário, UNIDERP

${ }^{4}$ Médico veterinário, Embrapa Gado de Corte, in memorian.

${ }^{5}$ Bolsista do CNPq.
} 
as respostas podem ser diferentes, em razão da maior necessidade de minerais em certas fases da gestação e lactação, às vezes coincidindo com a seca. Bovinos podem lançar mão das reservas ósseas de cálcio e de fósforo para manter as concentrações desses elementos adequadas para suportar processos metabólicos essenciais. Entretanto, se essa condição for mantida, a deficiência clínica será estabelecida.

Pesquisadores australianos consideram que em pastagens deficientes em fósforo, a suplementação de vacas em lactação com este elemento é imprescindível para a manutenção de bons índices de produtividade, mas observaram que a resposta das vacas gestantes pode ser bastante reduzida na época seca (RESOURCE CONSULTING SERVICES, 1986).

$A$ vaca parece responder à suplementação de $\mathrm{P}$ durante a lactação, aumentando a digestibilidade e o consumo de matéria seca, assim como a produção de leite (Fishwick et al., 1977; Call et al., 1987). A suplementação de vacas lactantes na estação seca torna-se eficiente se o nitrogênio também for suplementado (Bortolussi et al., 1996).

Alguns consideram especialmente contraproducente o fornecimento de $\mathrm{P}$ a vacas secas que estão perdendo peso. Aparentemente, a energia requerida para metabolização desse fósforo é maior que aquela necessária para utilização de $\mathrm{P}$ das reservas óssea, acentuando a deficiência de energia do animal (RESOURCE CONSULTING SERVICES, 1986). Ainda assim, Karn (2001) menciona provável benefício da suplementação de P na deficiência de proteína pela redução na incidência de botulismo.

Objetivou-se, neste trabalho, estudar a resposta à suplementação de cálcio e de fósforo com ou sem proteína e energia, durante a seca, sobre a produção de vacas de cria em pastejo.

\section{Material e Métodos}

Sessenta novilhas Nelore com diagnóstico positivo de prenhez foram distribuídas em três tratamentos, em blocos de dez vacas de acordo com o ano de nascimento (1994 e 1995), totalizando 20 fêmeas por tratamento.

A área experimental encontra-se na Embrapa
Gado de Corte, Campo Grande, MS. O clima pode ser considerado como tropical úmido (Aw), segundo a classificação de Köppen, com estação chuvosa no verão e seca no inverno. A precipitação média anual situa-se em torno de $1.500 \mathrm{~mm}$, sendo os meses de menor precipitação junho, julho e agosto. A temperatura média anual oscila de $19^{\circ} \mathrm{C}$ a $25^{\circ} \mathrm{C}$.

O experimento foi implantado em três piquetes de 22 ha cada com Brachiaria brizantha cv. Marandu, formada há cerca de dez anos em Latossolo Vermelho-Escuro, imperfeitamente drenado, de relevo plano. A taxa de lotação média foi de 0,94 unidade animal/ha. Os piquetes foram vedados em fevereiro/98 e as fêmeas, introduzidas na área em julho/98. O experimento iniciou-se em agosto/98. A área foi submetida à gessagem e calagem (gesso 613 kg/ha; calcário dolomítico, 2,27 t/ha) em setembro/98 e à adubação (NPK 2-50-20, 500 kg/ha; uréia $110 \mathrm{~kg} / \mathrm{ha}$ ) em janeiro/99. Os piquetes dispunham de água à vontade e cochos cobertos.

Os lotes de animais foram rotacionados nos piquetes a cada 15 dias.

A estação de monta (EM) teve duração de 90 dias (janeiro a março). Utilizaram-se três touros, que, após serem avaliados andrológicamente, foram distribuídos, um por tratamento, e rotacionados quinzenalmente entre os tratamentos. Apenas na estação de monta das vacas primíparas optou-se por utilizar a desmama interrompida (48 a 72 horas) para estimular o retorno ao cio. O diagnóstico de gestação foi realizado em maio/junho por palpação retal. Os bezerros foram desmamados entre 6 a 7 meses de idade. No intervalo de partos, consideraram-se apenas os dados de vacas que pariram em anos consecutivos.

Durante três anos experimentais completos, compreendidos entre 01 agosto/1998 e 01 agosto/2001, todas as vacas receberam mistura mineral completa ${ }^{1}(\mathrm{P}, \mathrm{S}$, $\mathrm{Cu}, \mathrm{Zn}, \mathrm{Co}, \mathrm{I}, \mathrm{Se}, \mathrm{Na}$ ), nas época das águas. Na seca, as vacas foram submetidas aos seguintes tratamentos:

MMC: mistura mineral completa todo o ano MM: mistura mineral sem fosfato bicálcico MMR: mistura mineral sem fosfato bicálcico + suplemento protéico-energético ${ }^{2}$

\footnotetext{
${ }^{1}$ Composição da mistura mineral: fosfato bicálcico, 57,923\%; sulfato de zinco, 2,041\%; sulfato de cobre, 0,454\%; sulfato de cobalto, 0,019\%; iodato de potássio, 0,008\%; selenito de sódio, 0,005\%; flor de enxofre, $7,240 \%$; cloreto de sódio, 31,310\% e melaço em pó, $1 \%$.

2 Suplemento protéico-energético (consumo médio por animal/dia): farelo de soja, 800 g; grão de milho triturado, $1500 \mathrm{~g}$ e carbonato de cálcio, $32 \mathrm{~g}$. Corresponde a cerca de $0,55 \%$ do peso vivo.
}

R. Bras. Zootec., v.33, n.6, p.2151-2160, 2004 (Supl. 2) 
O controle de consumo da mistura mineral foi mensal, obtido pela diferença de pesagem entre fornecido e sobra. O consumo da ração, fornecida diariamente durante o período da manhã, foi total (2,32 kg/cab/dia). Os períodos de seca compreenderam: 18/08/98 a 14/10/98, 09/06/99 a 03/11/99, 13/06/00 a 11/09/00 e 27/06/01 a 28/09/01.

Considera-se adequada a disponibilidade de matéria seca total para $B$. brizantha acima de 2.500 a $3.000 \mathrm{~kg} / \mathrm{ha}$ (Euclides et al., 2000). No presente experimento, as pastagens foram manejadas de forma a manter disponibilidade média acima de $2.500 \mathrm{~kg} / \mathrm{ha}$ durante todo o ano (Tabela 1). Como não foi possível adubar as pastagens antes do início do experimento, a área foi vedada em fevereiro/98, com a entrada das vacas no mesmo ano. Por esta ocasião, a disponibilidade média inicial foi de $4.892 \mathrm{~kg}$ de matéria seca total/ha, mas com elevada quantidade de material morto. O incremento observado na produção de matéria seca no primeiro ano experimental (fevereiro - junho/99) deveu-se à resposta à adubação. A seca de 1999 foi intensa e prolongada (Tabela 2) e a entrada de fogo em 26/06/99 comprometeu cerca de 1/3 da área experimental. Houve queda progressiva na disponibilidade de matéria seca nas pastagens, reflexo da não-reposição dos nutrientes retirados pelas plantas (Tabela 1).

Foram avaliados: condição corporal (escala 1 a 9; Corah et al. 1991) no início da seca, ao parto e à
Tabela 1 - Disponibilidade média de matéria seca (MS) total de $B$. brizantha sob pastejo, em várias épocas de coleta durante três anos consecutivos

Table 1 - Mean total dry matter (MS) availability of B. brizantha under grazing, at different collection times, during three consecutive years

\begin{tabular}{|c|c|c|}
\hline $\begin{array}{l}\text { Média } \\
\text { Mean }\end{array}$ & $\begin{array}{l}\text { kg MS/ha } \\
\text { kg/DM/ha }\end{array}$ & \\
\hline $\begin{array}{l}\text { Ano experimental } \\
\text { Experimental year }\end{array}$ & $\begin{array}{l}\text { Data de coleta } \\
\text { Date of collection }\end{array}$ & Total \\
\hline \multirow[t]{3}{*}{1} & 20/10/1998 & 5477 \\
\hline & 24/02/1999 & 5693 \\
\hline & 11/06/1999 & 7364 \\
\hline \multirow[t]{3}{*}{2} & 19/10/1999 & 3642 \\
\hline & $09 / 02 / 2000$ & 3360 \\
\hline & 07/06/2000 & 3727 \\
\hline \multirow[t]{3}{*}{3} & 25/09/2000 & 3056 \\
\hline & $19 / 12 / 2000$ & 3619 \\
\hline & 07/06/2001 & 2771 \\
\hline Média & & 4419 \\
\hline Mean & & \\
\hline
\end{tabular}

desmama; peso das matrizes no início e final da seca e ao parto; peso dos bezerros ao nascer e à desmama; avaliação do intervalo parto-concepção; e taxa de gestação ao final da EM.

A determinação da qualidade da forragem foi feita, no final da seca e das águas, em amostras obtidas por simulação de pastejo (Euclides et al., 1992) e disponibilidade de matéria seca (Haydock \&

Tabela 2 - Precipitação média mensal e anual, e média normal das observações na Embrapa Gado de Corte. Entre parênteses, meses em que houve diferenciação na suplementação entre tratamentos (seca) por, no mínimo, 10 dias

Table 2 - Mean monthly and annual precipitation, and normal means of the observations at Embrapa beef cattle. Between parenthesis, months with different (drought) supplementation among treatments for at least 10 days

\begin{tabular}{|c|c|c|c|c|c|}
\hline \multirow[b]{2}{*}{$\begin{array}{l}\text { Mês } \\
\text { Month }\end{array}$} & \multicolumn{3}{|c|}{$\begin{array}{l}\text { Precipitação mensal (mm) no ano } \\
\text { Monthly precipitation ( } \mathrm{mm} \text { ) in the year }\end{array}$} & \multirow[b]{2}{*}{$\begin{array}{l}\text { Média geral } \\
\text { Overall mean }\end{array}$} & \multirow[b]{2}{*}{$\begin{array}{c}\text { Média normal (1973/99) } \\
\text { Normal mean }\end{array}$} \\
\hline & $1(98 / 99)$ & $2(99 / 00)$ & $3(00 / 01)$ & & \\
\hline Agosto (August) & $(122)^{3}$ & (0) & (97) & 73 & 33 \\
\hline Setembro(September) & $(115)$ & $(65)$ & (132) & 104 & 84 \\
\hline Outubro (October) & (114) & (182) & 94 & 130 & 137 \\
\hline Novembro (November) & 84 & 94 & 180 & 119 & 168 \\
\hline Dezembro(December) & 148 & 131 & 204 & 161 & 225 \\
\hline Janeiro (January) & 199 & 169 & 171 & 179 & 278 \\
\hline Fevereiro (February) & 127 & 237 & 253 & 206 & 168 \\
\hline Março (March) & 188 & 271 & 118 & 192 & 145 \\
\hline Abril (April) & 38 & 41 & 78 & 52 & 104 \\
\hline Maio (May) & 31 & 40 & 101 & 57 & 107 \\
\hline Junho (June) & $(16)^{4}$ & $(8)^{5}$ & 40 & 21 & 49 \\
\hline Julho (July) & $(16)$ & (34) & $(43)^{6}$ & 31 & 30 \\
\hline Soma (Sum) & 1198 & 1272 & 1511 & 1325 & 1528 \\
\hline
\end{tabular}

\footnotetext{
R. Bras. Zootec., v.33, n.6, p.2151-2160, 2004 (Supl. 2)
} 
Shaw, 1975). Foram realizadas análises de proteína bruta e digestibilidade in vitro da matéria orgânica (Harris, 1970) e Ca e P (Fick et al., 1980).

Foi utilizado um delineamento de blocos ao acaso, com parcelas subdivididas no tempo, em que os blocos foram ano de nascimento das vacas (1994 e 1995). Os tratamentos foram alocados na parcela principal, as épocas de amostragem, na subparcela e o ano experimental, à sub-subparcela. Não foram estabelecidas repetições para os pastos. Análises de variância foram feitas utilizando-se o procedimento GLM do SAS Institute (SAS, 1985). Quando houve diferença significativa, as médias foram comparadas pelo teste de Tukey a $5 \%$ de probabilidade. As taxas de prenhez foram avaliadas pelo teste $\chi^{2}$.

\section{Resultados e Discussão}

A qualidade média das pastagens (Tabela 3) variou com a época do ano e com o ano de amostragem. No início da seca (junho) do primeiro ano, o teor de proteína bruta esteve abaixo de 7\%, o que poderia limitar o consumo de matéria seca e o desempenho animal (Minson, 1990). A quantidade de capim disponível aos animais possibilitou aos mesmos selecionar uma dieta da qualidade indicada pela amostragem e, talvez por essa razão, o efeito da ração sobre o peso e a condição corporal das vacas ao parto tenha sido pequeno (Tabela 4). Observaram-se efeitos positivos do arraçoamento neste primeiro ano sobre o intervalo de partos e as medidas ósseas, sendo o primeiro discutido logo adiante. Já no terceiro ano experimental, a precipitação acumulada dos meses de abril a junho foi cerca de 1,5 vezes maior que a ocorrida nos dois primeiros anos experimentais, resultando em melhor qualidade da pastagem em junho/01, e, portanto, com pouco efeito da ração.

A concentração de cálcio na forrageira, geralmente, esteve suficiente, apresentando teores acima de $0,28 \%$, garantindo adequado aporte deste elemento para as vacas em pastejo, independentemente da suplementação da dieta.

O terço médio da gestação corresponde à fase em que as necessidades de fósforo na dieta são consideradas menores (cerca de $10 \mathrm{~g} / \mathrm{cab} / \mathrm{dia}$ ou $0,12 \%$ de $\mathrm{P}$ ). Nas condições deste estudo,

Tabela 3 - Composição química de amostras de Brachiaria brizantha cv. Marandu coletadas por simulação de pastejo no início e meados das chuvas e início da seca: proteína bruta (PB), digestibilidade in vitro da matéria orgânica (DIVMO), fósforo $(P)$ e cálcio (Ca) na matéria seca

Table 3 - Chemical composition of Brachiaria brizantha cV. Marandu colected by grazing simulation in the beginning and middle of wet season and in the beginning of the dry season: crude protein (PB), in vitro digestibility of organic matter(DIVMO), phosphorus $(P)$ and calcium $(\mathrm{Ca})$ in the dry matter

\begin{tabular}{|c|c|c|c|c|c|}
\hline \multirow[b]{2}{*}{$\begin{array}{l}\text { Mês } \\
\text { Month }\end{array}$} & & \multicolumn{3}{|c|}{$\begin{array}{l}\text { Ano experimental } \\
\text { Experimental year }\end{array}$} & \multirow[b]{2}{*}{$\begin{array}{l}\text { Média gera } \\
\text { Total means }\end{array}$} \\
\hline & & $1(98 / 99)$ & $2(99 / 00)$ & $3(00 / 01)$ & \\
\hline Set/Out & PB, \% & 10,3 & 12,5 & 12,1 & 11,6 \\
\hline \multirow[t]{3}{*}{ Sept/Oct } & DIVMO, \% & 58,3 & 70,3 & 65,6 & 64,8 \\
\hline & $\mathrm{P}, \%$ & 0,14 & 0,19 & 0,18 & 0,17 \\
\hline & Сa, \% & 0,61 & 0,28 & 0,47 & 0,45 \\
\hline Dez/Fev & PB, \% & 11,2 & 9,3 & 8,3 & 9,6 \\
\hline \multirow[t]{3}{*}{ Dec/Feb } & DIVMO, \% & 54,6 & 62,1 & 57,8 & 58,2 \\
\hline & $\mathrm{P}, \%$ & 0,18 & 0,13 & 0,10 & 0,14 \\
\hline & Са, \% & 0,37 & 0,36 & 0,40 & 0,37 \\
\hline \multirow[t]{4}{*}{ JunJun } & PB, \% & 5,3 & 7,3 & 10,4 & 7,7 \\
\hline & DIVMO, \% & 44,2 & 47,7 & 56,5 & 49,5 \\
\hline & $\mathrm{P}, \%$ & 0,10 & 0,16 & 0,17 & 0,14 \\
\hline & $\mathrm{Ca}, \%$ & 0,56 & 0,57 & 0,46 & 0,53 \\
\hline Média geral de PB, \% & & 9,0 & 9,7 & 10,3 & 9,6 \\
\hline Global mean for $P B, \%$ & & & & & \\
\hline Média geral de DIVMO, \% & & 52,4 & 60,1 & 60,0 & 57,5 \\
\hline Global mean for DIVMO, \% & & & & & \\
\hline Média geral de P, \% & & 0,14 & 0,16 & 0,15 & 0,15 \\
\hline Global mean for P, \% & & & & & \\
\hline Média geral de Ca, \% & & 0,51 & 0,40 & 0,45 & 0,45 \\
\hline Global mean for P, \% & & & & & \\
\hline
\end{tabular}

R. Bras. Zootec., v.33, n.6, p.2151-2160, 2004 (Supl. 2) 
essa fase compreende de meados de maio a meados de agosto, plena estação seca. Apenas no primeiro ano, as concentrações de fósforo na pastagem estiveram inadequadas para atender às exigências das vacas nesta fase. O concentrado recebido pelo tratamento MMR na seca forneceu, em média, 10,3 g de P/cab/dia.

Vacas (Fishwick et al., 1977; Bass et al., 1981) e ovelhas (Braithwaite, 1983) em dietas deficientes em $\mathrm{P}$, com altas demandas para formação fetal no final da gestação, não têm respondido à suplementação de fósforo, mesmo quando há níveis adequados dos outros nutrientes (Ca, proteína etc) na dieta. Uma explicação aventada é de que o aumento da reabsorção óssea no final da gestação seria uma resposta fisiológica obrigatória, disponibilizando fósforo suficiente para atender os requisitos do animal. Assim, parte do fósforo suplementado ao animal, por meio da dieta, tornar-se-ia desnecessário e seria excretado nas fezes e na urina (Braithwaite, 1983).

O início da lactação corresponde à fase de maior demanda por fósforo. Cerca de 1.6 e 1.2 g P/L são secretados no leite por vacas e ovelhas, respectivamente (Ternouth, 1991; Ternouth \& Coates, 1997). Embora essa fase tenha ocorrido no meio da estação de chuvas, as concentrações de fósforo encontradas nas pastagens (Tabela 3; correspondendo a ingestão média estimada de P de 16,9; 12,2 e 9,4 g/cab/dia, nos anos 1,2 e 3, respectivamente) foram insuficientes para atender às demandas das vacas (estimada em $17,3 \mathrm{~g} / \mathrm{cab} / \mathrm{d})$. No experimento, todas as vacas tinham acesso à mistura mineral contendo fósforo

Tabela 4 - Médias de peso vivo (PV) e condição corporal (CC) das vacas e peso vivo dos bezerros ao parto nos tratamentos MMC (mistura mineral completa o ano todo), MM (mistura mineral completa nas águas e mistura mineral sem fosfato bicálcico na seca) e MMR (mistura mineral completa nas águas e mistura mineral sem fosfato bicálcico + concentrado) na seca

Table 4 - Means of liveweight (PV) and body score (CC) of cows and liveweight of calves at birth on complete mineral mixtures $(M M C)$ all year round or mineral mixtures lacking dicalcium phosphate, supplemented (MMR) or not (MM) with concentrate, during the dry season

\begin{tabular}{|c|c|c|c|c|c|}
\hline \multirow[b]{2}{*}{$\begin{array}{l}\text { Tratamento } \\
\text { Treatment }\end{array}$} & \multirow[b]{2}{*}{$\begin{array}{l}\text { Médias } \\
\text { Means }\end{array}$} & \multicolumn{3}{|c|}{$\begin{array}{l}\text { Ano experimental } \\
\text { Experimental year }\end{array}$} & \multirow[b]{2}{*}{$\begin{array}{l}\text { Média gera } \\
\text { Total mean }\end{array}$} \\
\hline & & $1(98 / 99)$ & $2(99 / 00)$ & $3(00 / 01)$ & \\
\hline \multirow[t]{3}{*}{ MMC } & $\begin{array}{l}\text { PV da vaca ao parto, kg } \\
\text { Cows } P V \text { at parturition }\end{array}$ & 369,3 & 376,8 & 423,8 & 390,0 \\
\hline & CC ao parto & 5,1 & 4,8 & 5,2 & 5,0 \\
\hline & $\begin{array}{l}\text { CC at parturition } \\
\text { PV de bezerro ao nascer, } \mathrm{kg} \\
\text { Calves'PV at birth, } \mathrm{kg}\end{array}$ & 30,4 & 29,6 & 28,2 & 29,4 \\
\hline \multirow[t]{3}{*}{ MM } & $\begin{array}{l}\text { PV da vaca ao parto, } \mathrm{kg} \\
\text { Cows } P V \text { at parturition }\end{array}$ & 391,2 & 385,6 & 434,4 & 403,7 \\
\hline & $\begin{array}{l}\text { CC ao parto } \\
\text { CC at parturition }\end{array}$ & 5,1 & 4,8 & 5,1 & 5,0 \\
\hline & $\begin{array}{l}\mathrm{PV} \text { de bezerro ao nascer, } \mathrm{kg} \\
\text { Calves } P V \text { at birth, } \mathrm{kg}\end{array}$ & 30,9 & 29,7 & 28,8 & 29,8 \\
\hline \multirow[t]{3}{*}{ MMR } & $\begin{array}{l}\text { PV da vaca ao parto, } \mathrm{kg} \\
\text { Cows'PV at parturition }\end{array}$ & 387,7 & 411,6 & 461,5 & 420,3 \\
\hline & $\begin{array}{l}\text { CC ao parto } \\
\text { CC at parturition }\end{array}$ & 5,1 & 5,3 & 5,6 & 5,3 \\
\hline & $\begin{array}{l}\text { PV de bezerro ao nascer, } \mathrm{kg} \\
\text { Calves } P V \text { at birth, } \mathrm{kg}\end{array}$ & 29,5 & 28,5 & 28,1 & 28,7 \\
\hline \multicolumn{2}{|c|}{$\begin{array}{l}\mathrm{PV} \text { médio da vaca ao parto, } \mathrm{kg} \\
\text { Mean calves } P V \text { at parturition, } \mathrm{kg}\end{array}$} & $382,7^{b}$ & $391,3^{b}$ & $439,9^{\mathrm{a}}$ & 404,5 \\
\hline \multicolumn{2}{|c|}{$\begin{array}{l}\text { CC média ao parto } \\
\text { Mean CC at parturition }\end{array}$} & $5,1 \mathrm{ab}$ & $5,0^{b}$ & $5,3^{a}$ & 5,1 \\
\hline \multicolumn{2}{|c|}{$\begin{array}{l}\text { PV médio de bezerro ao nascer } \\
\text { Mean calves'PV at birth, } \mathrm{kg}\end{array}$} & $30,2^{\mathrm{a}}$ & $29,2^{a b}$ & $28,4^{\mathrm{b}}$ & 29,3 \\
\hline
\end{tabular}

Letras diferentes $(a, b)$ na mesma linha indicam diferença estatística significativa, pelo teste Tukey (5\%).

Different letter $(a, b)$, in the same row, indicate significant statistical differences between the means.

R. Bras. Zootec., v.33, n.6, p.2151-2160, 2004 (Supl. 2) 
suplementar durante a estação chuvosa, com consumo médio estimado de P da ordem de 6,5 g/cab/dia. Esse suplemento foi formulado para fornecer fósforo em nível que não fosse limitante, porém, menores concentrações de fósforo poderiam ter sido utilizadas, sem prejuízo à saúde e à produção.

O consumo médio de suplemento mineral (UA/d) foi de $63 \mathrm{~g}$ nas chuvas; nas secas, as médias foram de $43 \mathrm{~g}$ (MMC), $36 \mathrm{~g}$ (MM) e $25 \mathrm{~g}$ (MMR). Embora essas quantidades fossem, às vezes, menores que 0 consumo esperado (cerca de $85 \mathrm{~g}$ para MMC e $35 \mathrm{~g}$ para MM e MMR), permitiam um aporte significativo de macro e microelementos. Cabe lembrar que MM não inclui P e Ca suplementar. O maior consumo dos suplementos minerais nas chuvas foi também observado por S'Thiago et al. (2000), associado à melhoria na qualidade das pastagens.

Durante todo o experimento, as vacas apresentaram condição corporal (CC) em torno de cinco (Tabela 4). Saturnino \& Dias (1993) observaram que as vacas zebuínas obtiveram os melhores desempenhos reprodutivos quando pariram com CC igual ou superior a 4,5. Nesse estudo, quanto melhor a condição corporal no início da estação de monta, melhor o desempenho reprodutivo das vacas.

O peso médio permaneceu próximo de $400 \mathrm{~kg}$ e as vacas ganharam peso com o avanço da idade (Tabela 4), comprovando que as pastagens disponíveis e a suplementação oferecida atenderam às suas demandas nutricionais.
O fornecimento de ração e mistura mineral completa durante a estação seca não influenciaram os pesos dos bezerros ao nascimento (Tabela 4). Isto indica que a dieta das vacas foi suficiente para não limitar o crescimento fetal. Houghton et al. (1990), no entanto, observaram que vacas alimentadas com dietas deficientes em energia pariram bezerros mais leves que vacas em dietas adequadas. Revisando os fatores que afetam o peso ao nascer, Holland \& Odde (1992) concluíram que o peso do bezerro ao nascer não deve ser afetado pela dieta da mãe, a não ser quando submetida à severa deficiência nutricional durante a gestação.

O reduzido número de vacas impossibilita avaliações precisas do efeito dos tratamentos sobre o desempenho reprodutivo. Wu \& Satter (2000) estimaram serem necessárias pelo menos 250 vacas por tratamento para se detectar uma diferença de $10 \%$ nas medidas reprodutivas com grau de confiança de 95\%.

O número de vacas prenhes/total de vacas para os tratamentos MMC, MM e MMR foi de: 14/20 e 19/20, 15/19 e 17/19 e 14/19 e 18/19, respectivamente, durante os anos de 1999 e 2000.

O peso ao primeiro parto é considerado o mais importante fator influenciando a prenhez na reconcepção de vacas primíparas. Estima-se que vacas que perdem de 25 a $30 \%$ de seu peso adulto tenham a reprodução prejudicada (atrofia de órgãos reprodutivos, menor secreção hormonal, anestro). Para fêmeas mais leves e com condição corporal

Tabela 5 - Taxas de gestação frente aos tratamentos nos anos de 1999 e 2000 nos tratamentos MMC (mistura mineral completa o ano todo), MM (mistura mineral completa nas águas e mistura mineral sem fosfato bicálcico na seca) e MMR (mistura mineral completa nas águas e mistura mineral sem fosfato bicálcico + concentrado) na seca

Table 5 - Pregnancy rates due to treatments in the years 1999 and 2000 on complete mineral mixtures (MMC) all year round or mineral mixtures lacking dicalcium phosphate, supplemented (MMR) or not (MM) with concentrate, during the dry season

\begin{tabular}{lccccc}
\hline $\begin{array}{l}\text { Tratamento } \\
\text { Treatment }\end{array}$ & \multicolumn{2}{c}{1999} & & 2000 \\
\cline { 2 - 3 } \cline { 5 - 6 } & $\begin{array}{c}\text { Vacas prenhes (total) } \\
\text { Pregnat cows (total) }\end{array}$ & $\begin{array}{c}\text { Reconcepção, \% } \\
\text { Reconception, \% }\end{array}$ & & $\begin{array}{c}\text { Vacas prenhes (total) } \\
\text { Pregnat cows (total) }\end{array}$ & $\begin{array}{c}\text { Reconcepção, \% } \\
\text { Reconception, \% }\end{array}$ \\
\hline MMC & $14(20)$ & 70,0 & $19(20)$ & 95 \\
MM & $15(19)$ & 78,9 & $17(19)$ & 89,5 \\
MMR & $14(19)$ & 73,7 & $18(19)$ & 94,7 \\
Médias & & 74,1 & & 93,1 \\
Means & & & & \\
\hline
\end{tabular}

Ano $1 \chi^{2}$ calculado $0,757(P>0,05)$.

Year 1 calculated $\chi^{2} .757(P>.05)$.

Ano $2 \chi^{2}$ calculado $0,899(P>0,05)$.

Year 2 calculated $\chi^{2} .899(P>.05)$.

R. Bras. Zootec., v.33, n.6, p.2151-2160, 2004 (Supl. 2) 
Tabela 6 - Média de intervalo de partos (IP) nos anos 2 (1998-1999) e 3 (1999-2000) nos tratamentos MMC (mistura mineral completa o ano todo), MM (mistura mineral completa nas águas e mistura mineral sem fosfato bicálcico na seca) e MMR (mistura mineral completa nas águas e mistura mineral sem fosfato bicálcico + concentrado) na seca

Table 6 - Mean calving interval (IP) for years 2 (1998-1999) and 3 (1999-2000) on complete mineral mixtures (MMC) all year round or mineral mixtures lacking dicalcium phosphate, supplemented (MMR) or not (MM) with concentrate, during the dry season

\begin{tabular}{|c|c|c|c|}
\hline \multirow{2}{*}{$\begin{array}{l}\text { IP, dias } \\
\text { IP, days } \\
\text { Tratamento } \\
\text { Treatment }\end{array}$} & \multicolumn{2}{|c|}{$\begin{array}{l}\text { Ano experimental } \\
\text { Experimental year }\end{array}$} & \multirow[b]{2}{*}{$\begin{array}{l}\text { Média geral } \\
\text { Total means }\end{array}$} \\
\hline & 2 & 3 & \\
\hline MMC & 370 & 359 & 364 \\
\hline MM & 377 & 362 & 370 \\
\hline MMR & 358 & 370 & 364 \\
\hline Médias & 368 & 364 & 366 \\
\hline Means & & & \\
\hline
\end{tabular}

moderada, entretanto, menor porcentagem de perda de peso (6-10\%) nas primeiras semanas do pós-parto é capaz de levar ao anestro (Ferreira, 1993). No presente trabalho, as vacas pariram no primeiro ano com cerca de $383 \mathrm{~kg}$. A taxa média de reconcepção das primíparas foi de 74,1\% (Tabela 5), bastante superior à média nacional, situada em torno de 30\% a 40\% (Pacola et al., 1997), e não houve diferença significativa entre os tratamentos.

Os tratamentos não influenciaram os intervalos de partos das vacas (Tabela 6; $\mathrm{P}>0,05$ ), mas houve interação $(\mathrm{P}<0,05)$ entre tratamento e ano. A suplementação com ração pareceu favorecer a reconcepção de vacas primíparas, que apresentaram, em média, 12 e 19 dias a menos de intervalo de partos que os tratamentos MMC e MM, respectivamente. Segundo Ruas et al. (2000), dietas de bom nível alimentar no pré e pós-parto proporcionam o retorno da atividade ovariana cíclica no período de 60 a 90 dias pós-parto, o que leva a intervalos de parto inferiores a 365 dias, promovendo níveis ótimos de exploração na atividade de pecuária de corte. Independentemente de tratamento, a média de intervalo de partos observada neste experimento foi de 366 dias.

As vacas suplementadas com ração na seca tenderam a apresentar, em média, maior peso e CC à desmama, mas os resultados não diferiram significa- tivamente $(\mathrm{P}>0,05)$, e não houve influência no peso dos bezerros à desmama (Tabela 7; $\mathrm{P}>0,05$ ). Esses resultados permitem postular que não houve diferença marcante na produção de leite de matrizes suplementadas ou não durante a seca, e as vacas dos três tratamentos tiveram tempo suficiente para recuperar a CC durante o período de chuvas, o que está de acordo com os dados de Fordyce et al. (1997).

Observa-se incremento no peso das vacas com o passar do tempo, reflexo de seu amadurecimento, sem influência significativa do tempo no peso dos bezerros desmamados. As vacas apresentaram melhor condição corporal à desmama a partir da segunda desmama.

Quando o sexo do bezerro foi usado como co-variável na análise estatística, houve efeito de bloco idade das vacas) sobre o peso do bezerro à desmama $\mathrm{P}<0,001)$. As vacas nascidas em 1994 desmamaram, em média, bezerros 4,3 kg mais pesados que as vacas ais jovens. A separação de bezerros machos e fêmeas mostrou que esse efeito foi significativo $(\mathrm{P}<0,05)$ apenas para as bezerras. Vacas mais velhas desmamaram bezerras, em média, $8,1 \mathrm{~kg}$ mais pesadas. Observou-se também tendência de as vacas de $\mathrm{MM}$ a desmamarem bezerros mais pesados que aquelas de $\operatorname{MMR}(\mathrm{P}=0,06)$, quando o sexo do bezerro foi usado como co-variável.

Quando bezerros machos e fêmeas foram separados para análise estatística, observou-se o efeito de tratamento no peso da vaca à desmama de machos $(\mathrm{P}<0,05)$. Vacas em MM estavam, em média, $25 \mathrm{~kg}$ mais pesadas à desmama que as vacas em MMC, estando MMR em um patamar intermediário.

A maior parte dos problemas reprodutivos devese ao consumo insuficiente de energia e proteína, mas não pode haver dúvidas de que uma dieta adequada em fósforo é também necessária para garantir a saúde e a eficiência reprodutiva de fêmeas bovinas. A deficiência de minerais ocasiona redução no consumo e na utilização do alimento com efeitos indiretos na eficiência reprodutiva, o que pode dificultar a identificação de efeitos específicos. A deficiência de fósforo tem sido relacionada com a baixa taxa de concepção, anestro, estro irregular, redução na atividade ovariana, alta incidência de cistos foliculares e queda geral na fertilidade (Maas, 1987; Hurley \& Doane, 1989), o que não foi observado neste estudo.

A resposta produtiva e reprodutiva de vacas à suplementação com fósforo tem sido questionada em outros estudos. Em alguns casos, foram observadas 
Tabela 7 - Peso vivo (PV) e condição corporal (CC) das vacas à desmama e peso dos bezerros desmamados (corrigidos para 205 dias) nos tratamentos MMC (mistura mineral completa o ano todo), MM (mistura mineral completa nas águas e mistura mineral sem fosfato bicálcico na seca) e MMR (mistura mineral completa nas águas e mistura mineral sem fosfato bicálcico + concentrado) na seca

Table 7 - Liveweight (PV) and body score (CC) of the cows at weaning and liveweight of weaned calves (corrected for 205 days) on complete mineral mixtures (MMC) all year round or mineral mixtures lacking dicalcium phosphate, supplemented $(M M R)$ or not $(M M)$ with concentrate, during the dry season

\begin{tabular}{|c|c|c|c|c|c|}
\hline \multirow[b]{2}{*}{$\begin{array}{l}\text { Tratamento } \\
\text { Treatment }\end{array}$} & \multirow[b]{2}{*}{$\begin{array}{l}\text { Médias à desmama } \\
\text { Means at weaning }\end{array}$} & \multicolumn{3}{|c|}{$\begin{array}{l}\text { Ano experimental } \\
\text { Experimental year }\end{array}$} & \multirow[b]{2}{*}{$\begin{array}{l}\text { Média gera } \\
\text { Total means }\end{array}$} \\
\hline & & $1(98 / 99)$ & $2(99 / 00)$ & $3(00 / 01)$ & \\
\hline \multirow[t]{3}{*}{ MMC } & $\begin{array}{l}\text { PV de vacas, kg } \\
P V \text { of cows }\end{array}$ & 375,9 & 396,2 & 437,5 & 403,2 \\
\hline & $\mathrm{CC}$ & 4,9 & 5,3 & 5,0 & 5,1 \\
\hline & $\begin{array}{l}\text { PV de bezerros, } \mathrm{kg} \\
\mathrm{PV} \text { of calves }\end{array}$ & 178,1 & 181,7 & 187,6 & 182,5 \\
\hline \multirow[t]{3}{*}{ MM } & $\begin{array}{l}\text { PV de vacas, kg } \\
P V \text { of cows }\end{array}$ & 387,2 & 392,9 & 466,0 & 415,4 \\
\hline & $\mathrm{CC}$ & 4,8 & 4,8 & 5,3 & 5,0 \\
\hline & $\begin{array}{l}\text { PV de bezerros, kg } \\
P V \text { of cows }\end{array}$ & 194,1 & 177,8 & 190,2 & 187,4 \\
\hline \multirow[t]{3}{*}{ MMR } & $\begin{array}{l}\text { PV de vacas, kg } \\
P V \text { of cows }\end{array}$ & 387,2 & 411,8 & 455,7 & 418,2 \\
\hline & CC & 4,9 & 5,5 & 5,6 & 5,3 \\
\hline & $\begin{array}{l}\text { PV de bezerros, } \mathrm{kg} \\
P V \text { of calves }\end{array}$ & 189,1 & 175,7 & 180,1 & 181,6 \\
\hline \multirow{4}{*}{$\begin{array}{l}\text { Médias } \\
\text { Means }\end{array}$} & PV de vacas, kg & $383,4^{b}$ & $400,3^{b}$ & $453,1^{\mathrm{a}}$ & 407,3 \\
\hline & $P V$ of cows & & & & \\
\hline & CC & $4,9^{b}$ & $5,2^{\mathrm{a}}$ & $5,3^{\mathrm{a}}$ & 5,1 \\
\hline & $\begin{array}{l}\text { PV de bezerros, kg } \\
P V \text { of calves }\end{array}$ & 187,1 & 178,4 & 185,9 & 184,1 \\
\hline
\end{tabular}

Letras diferentes, na mesma linha, indicam diferença estatística.

Different letter $(a, b)$, in the same row, indicate statistical differences between the means.

tendências à resposta reprodutiva em vacas suplementadas com fósforo (S’Thiago et al., 2000), mas é possível que em alguns desses trabalhos um número insuficiente de fêmeas tenha sido utilizado para permitir discriminação estatística do efeito de tratamentos (Wu \& Satter, 2000).

Alguns trabalhos (Fordyce et al., 1997, Sasser et al., 1988) têm mostrado melhoras na taxa de concepção e redução no período de serviço de animais suplementados com energia e proteína durante o préparto, provavelmente por melhora da CC dos animais ao parto, embora o mecanismo pelo qual a suplementação melhora a fertilidade não seja totalmente conhecido. Jolly et al. (1994) indica que o estresse nutricional atua diretamente e/ou indiretamente no eixo hipotálamo-hipófise-ovários, suprimindo o reinício da atividade ovariana pós-parto e afetando a fertilidade. Neste trabalho, os animais provavelmente não sofreram estresse nutricional, proporcio- nado pela adequada disponibilidade de matéria seca e nutrientes oferecidos pelas pastagens e suplementação, o que proporcionou as adequadas taxas de fertilidade observadas.

Uma série de mecanismos homeostáticos garante que o fósforo na dieta seja aproveitado ao máximo (Ternouth, 1991). A disponibilidade de outros nutrientes, especialmente de proteína e cálcio, influencia a eficiência da utilização do fósforo da dieta (Little, 1984) e, com isso, a resposta à suplementação (Van Niekerk, 1975). Nesta linha, a capacidade da fêmea de lançar mão de suas reservas orgânicas de fósforo poderia reduzir sua resposta ao fósforo suplementar (Call et al., 1986; S’Thiago et al., 2000), sobretudo em experimentos de curta duração. Brodison et al. (1989) consideram que os efeitos da deficiência de fósforo são improváveis de ocorrer a menos que o consumo do elemento seja muito baixo e já tenham aparecido sintomas clínicos de deficiência. 
Outro ponto a ser considerado é a possibilidade do capim já conter nutrientes em quantidades suficientes para atender às exigências da fêmea. Alguns pesquisadores consideram as estimativas de exigências nutricionais de fósforo superestimadas (Call et al., 1978; Call et al., 1986; Coates \&Ternouth, 1992; Wu et al., 2001) ou mesmo que deveriam ser revistas considerando também o fluxo de minerais do osso (Braithwaite, 1983).

Neste estudo, observou-se, a partir de meados do segundo ano experimental, crescimento e erosão de casco em vacas dos tratamentos MM e MMR. Foi diagnosticada laminite pela avaliação clínica. A laminite tem etiologia multi-fatorial. Os principais fatores que predispõem a laminite no bovino são doença sistêmica, nutrição, manejo, parição, idade, crescimento, genética, conformação e comportamento (Vermunt \& Greenough, 1994). Não foi possível identificar inequivocamente a causa das lesões, mas a doença está associada a mudanças súbitas na dieta. Embora a laminite seja geralmente associada a vacas leiteiras e a bovinos confinados, alta incidência de laminite (59\%) em gado de corte em pastejo foi descrita por Mgassa et al. (1984), na África.

\section{Conclusões}

Com a lactação ocorrendo durante a época de chuvas, quando todas as vacas receberam a mistura mineral completa e a forrageira apresentava concentrações adequadas de proteína e energia, as vacas recuperaram a condição corporal, compensando possíveis deficiências nutricionais ocorridas durante a seca, reduzindo os efeitos da suplementação. Entretanto, vacas primíparas se beneficiaram da suplementação com ração, na seca, apresentando menor intervalo de partos. A ausência de suplementação de $\mathrm{P}$ durante o período seco não acarretou prejuízos significativos nas taxas reprodutivas dos animais.

\section{Agradecimento}

Ao Dr. Rafael Geraldo de O. Alves, pela orientação estatística inicial, ao Prof. Charles Martins, pelo exame clínico das vacas, e aos Srs. Ernani Miranda da Fonseca e Jacir Vieira de Barros, pelo auxílio nos trabalhos de campo.

\section{Literatura Citada}

BASS, J.M.; FISHWICK, G.; HEMINGWAY, R.G. et al. The effects of supplementary phosphorus on the voluntary consumption and digestibility of a low phosphorus straw-based diet given to beef-cows during pregnancy and early lactation. Journal of Agricultural Science, v.97, p.365-372, 1981.

BORTOLUSSI, G.; TERNOUTH, J.H.; Mc MENIMAN, N.P. Dietary nitrogen and phosphorus depletion in cattle and their effects on liveweight gain, blood metabolite concentrations and phosphorus kinetics. Journal of Agricultural Science, v.126, n.4, p.493-501, 1996.

BRAITHWAITE, G.D. Calcium and phosphorus requirements of the ewe during pregnancy and lactation. 2. Phosphorus. British Journal of Nutition, v.50, n.3, p.723-36, 1983.

BRODISON, J.A.; GOODDALL, E.A.; ARMSTRONG, J.D. et al. Influence of dietary phosphorus on the performance of lactating dairy cattle. Journal of Agricultural Science, v.112, p.303-311, 1989.

CALL, J.W.; BUTCHER, J.E.; BLAKE, J.T. et al. Phosphorus influence on growth and reproduction of beef cattle. Journal of Animal Science, v.47, n.1, p.216-25, 1978.

CALL, J.W.; BUTCHER, J.E.; SHUPE, J.L. et al. Dietary phosphorus for beef cows. American Journal of Veterinary Research, v.47, n.2, p.475-81, 1986.

CALL, J.W.; BUTCHER, J.E.; SHUPE, J.L. et al. Clinical effects of low dietary phosphorus concentrations in feed given to lactating dairy cows. American Journal of Veterinary Research, v.48, n.1, p.133-136, 1987.

COATES, D.B.; TERNOUTH, J.H. Phosphorus kinetics of cattle grazing tropical pastures and IMPLICATIONS for the estimation of their phosphorus requirements. Journal of Agricultural Science, v.119, n.3, p.401-409, 1992.

CORAH, L.R.; HOUGHTON, P.L.; LEMENAGER, R.P. et al. Feeding your cows by body condition. Kansas State University, Cooperative Extension Service, 1991. Disponível em: < http://www.oznet.ksu.edu/library/LVSTK2/ C842.pdf>. Acesso em: 25 Mai. 1998.

EUCLIDES, V.P.B.; CARDOSO, E.G.; MACEDO, M.C.M. et al. Consumo voluntário de Brachiaria decumbens cv. Basilisk e Brachiaria brizantha cv. Marandu sob pastejo. Revista Brasileira de Zootecnia, v.29, n.6, p.2200-2208, 2000.

EUCLIDES, V.P.B.; MACEDO, M.C.M.; OLIVEIRA, M.O. Avaliação de diferentes métodos de amostragem [para se estimar o valor nutritivo de forragens] sob pastejo. Revista da Sociedade Brasileira de Zootecnia, v.21, n.4, p.691-702, 1992.

FERREIRA, A.M. Nutrição e atividade ovariana em bovinos: uma revisão. Pesquisa Agropecuária Brasileira, v.28, n.9, p.1077-1093, 1993.

FICK, K.R.; McDOWELL, L.R.; MILES, J.H. et al. Métodos de análises de minerais em tecidos de animais e de plantas. 2.ed. Gainesville: University of Florida, 1980. Paginação descontínua.

FISHWICK, G.; FRASER, J.; HEMINGWAY, R.G. et al. The effects of dietary phosphorus inadequacy during pregnancy and lactation on the voluntary intake and digestibility of oat straw by beef cows and the performance of their calves. Journal of Agricultural Science, v.88, n.1, p.143-150, 1977. 
FORDYCE, G.; FITZPATRICK, L.A.; MULLINS, T.J. et al. Prepartum supplementation effects on growth and fertility in Bos indicus-crosscows. Australian Journal of Experimental Agriculture, v.37, p.141-149, 1997.

HARRIS, L.E. Os métodos químicos e biológicos empregados na análise de alimentos. Gainesville: University of Florida, 1970. Paginação descontínua.

HAYDOCK, K.P. ; SHAW, N.H. The comparative yield method for estimating dry matter yield of pasture. Australian Journal of Experimental Agriculture and Animal Husbandry, v.15, p.663-670, 1975.

HOLLAND, M.D.; ODDE, K.G. Factors affecting calf birth weight: a review. Theriogenology, v.38, n.5, p.769-798, 1992.

HOUGHTON, P.L.; LEMENAGER, R.P.; HORSTMAN, L.A. et al. Effects of body composition, pre- and postpartum energy level and early weaning on reproductive performance of beef cows and preweaning calf gain. Journal of Animal Science, v.68, n.5, p.1438-46, 1990.

HURLEY, W.L. ; DOANE, R.M. Recent developments in the roles of vitamins and minerals in reproduction. Journal of Dairy Science, v.72, n.3, p.784-804, 1989.

JOLLY, P.D.; FITZPATRICK, L.A.; Mc DOUGALL, S. et al. Physiological effects of undernutrition on postpartum anoestrum in cows. Journal of Reproduction and Fertility, v.49, p.477-92, 1994. supplement

KARN, J.F. Phosphorus nutrition of grazing cattle: a review. Animal Feed Science and Technology, v.89, p.133-153, 2001.

LITTLE, D.A. Utilization of minerals . In: HACKER, J.B. (Ed.) Nutritional limits to animal production from pastures. Sta. Lucia, Queensland. Farnham Royal: CSIRO, 1984. p.259-283.

MAAS, J. Relationship between nutrition and reproduction in beef cattle. Veterinary Clinical North America Food Animal Practice, v.3, n.3, p.633-646, 1987.

MGASSA, M.N.; AMAYA-POSADA, G.; HESSELHOLT, M. Pododermatitis aseptica diffusa (laminitis) in free range beef cattle in tropical Africa. Veterinary Record, v.115, n.16, p.413-414, 1984.

MINSON, D.J. Forage in ruminant nutrition. San Diego: Academic Press, 1990. 483p.

PACOLA, L.J.; FIGUEIREDO, L.A.; RAZOOK, A.G. et al. Fertilidade de fêmeas nelore suplementadas nas fases pré e pós-desmama . In: REUNIÃO ANUAL DA SOCIEDADE BRASILEIRA DE ZOOTECNIA. 34., Juiz de Fora. Anais... Juiz de Fora: Sociedade Brasileira de Zootecnia, 1997. p.271-273.

RESOURCE CONSULTING SERVICES. A review of phosphorus requirements of grazing cattle in North Australia. Darwin: Coopers Animal Health Australia Ltda., 1986. 12p.

RUAS, J.R.M.; TORRES, C.A.A.; BORGES, L.E. et al. Efeito da suplementação protéica a pasto sobre a eficiência reprodutiva e concentrações sangüíneas de colesterol, glicose e uréia, em vacas Nelore. Revista Brasileira de Zootecnia, v.29, n.6, p.2042-2050, 2000.

S'THIAGO, L.R.L.; MORAES, S.S.; NICODEMO, M.L.F. et al. Efeito do fósforo suplementar sobre o desempenho reprodutivo de vacas de corte em pastagem de Brachiaria humidicola. Pesquisa Agropecuária Brasileira, v.35, n.2, p.449-456, 2000.
STATISTICAL ANALYSES SYSTEM - SAS INSTITUTE. Statistical analysis system user's guide: basics. Cary: 1985. 1290p.

SASSER, R.G.; WILLIAMS, R.J.; BULL, R.C. et al. Pospartum reproductive performance in crude protein restricted beef cows: return to estrus and conception. Journal of Animal Science, v.66, p.3033-3039, 1988.

SATURNINO, H.M.; DIAS, F.M.G.N. Condição corporal e eficiência reprodutiva em bovinos. In. CONGRESSO BRASILEIRO DE REPRODUÇÃO ANIMAL, 10., 1993, Belo Horizonte. Anais... Belo Horizonte: Colégio Brasileiro de Reprodução Animal, 1993. v.2, p.153-167.

SIMMS, D.D.; BLASI, D.A.; BOLZE, R.P. et al. Beef cow nutrition guide. Cooperative Extension Service, Kansas State University, 1993. Disponível em: $<$ http://www.lib.iastate.edu/agric/expbcow.html $>$. Acesso em: 22 mai.1998.

SOUSA, J.C.D.; GOMES, R.F.C.; ROSA, I.V. et al. Resposta de novilhos nelorados à suplementação mineral em pastagens de capim-colonião. Pesquisa Agropecuária Brasileira, v.18, n.3, p.311-318, 1983.

SOUSA, J.C.D.; GOMES, R.F.C.; SILVA, J.M.D. et al. Efeito da suplementação mineral de novilhos de corte em pastagens adubadas de capim Colonião. Pesquisa Agropecuária Brasileira, v.20, n.2, p.259-269, 1985.

TERNOUTH, J.H. The kinetics and requirements of phosphorus in ruminants. Recent Advances on the Nutrition of Herbivores, v.15, p.143-151, 1991. Separata.

TERNOUTH, J. H.; COATES, D. B. Phosphorus homeostasis in grazing breeder cattle. Journal of Agricultural Science, v.128, n.3, p.331-337. 1997.

TOKARNIA, C.H. ; DOBEREINER, J. Doenças causadas por deficiências minerais em bovinos em regime de campo no Brasil. In: SIMPOSIO LATINO-AMERICANO SOBRE PESQUISA EM NUTRICAO MINERAL DE RUMINANTES EM PASTAGENS, 1976, Belo Horizonte. Anais... [s. 1.]: UFMG/UFV/ESLAV/EPAMIG/USAID, [1976?].

Van NIEKERK, B.D.H. Suplementacion del ganado en pastoreo. In: SEMINÁRIO SOBRE EL POTENCIAL PARA LA PRODUCCIÓN DE GANADO DE CARNE EM AMERICA TROPICAL, 1974, Trabajos. Cali: CIAT, 1975.

VERMUNT, J.J.; GREENOUGH, P.R. Predisposing factors of laminitis in cattle. British Veterinary Journal, v.150, n.2, p.151-64, 1994.

WU, Z.; SATTER, L.D. Milk production and reproductive performance of dairy cows fed two concentrations of phosphorus for two years. Journal of Dairy Science, v.83, n.5, p.1052-1063, 2000.

WU, Z.; SATTER, L.D.; BLOHOWIAK, A.J. et al. Milk production, estimated phosphorus excretion, and bone characteristics of dairy cows fed different amounts of phosphorus for two or three years. Journal of Dairy Science, v.84, n.7, p.1738-48, 2001. 